\title{
The effectiveness of extracorporeal shock wave therapy for the treatment of lower limb ulceration: a systematic review
}

\author{
Paul A Butterworth ${ }^{1,2^{*}}$, Tom P Walsh ${ }^{3}$, Yvonne D Pennisi ${ }^{1}$, Anna D Chesne ${ }^{1}$, Christoph Schmitz ${ }^{4}$ \\ and Susan A Nancarrow ${ }^{1}$
}

\begin{abstract}
Extracorporeal shock wave therapy has been reported as an effective treatment for lower limb ulceration. The aim of this systematic review was to investigate the effectiveness of extracorporeal shock wave therapy for the treatment of lower limb ulceration.

Five electronic databases (Ovid MEDLINE, CINAHL, Web of Knowledge, Scopus and Ovid AMED) and reference lists from relevant studies were searched in December 2013. All study designs, with the exception of case-reports, were eligible for inclusion in this review. Assessment of each study's methodological quality was performed using the Quality Index tool. The effectiveness of studies was measured by calculating effect sizes (Cohen's $d$ ) from means and standard deviations.

Five studies, including; three randomised controlled trials, one quasi-experimental study and one case-series design met our inclusion criteria and were reviewed. Quality assessment scores ranged from 38 to 63\% (mean 53\%). Improvements in wound healing were identified in these studies following extracorporeal shock wave therapy. The majority of wounds assessed were associated with diabetes and the effectiveness of ESWT as an addition to standard care has only been assessed in one randomised controlled trial.

Considering the limited evidence identified, further research is needed to support the use of extracorporeal shock wave therapy in the treatment of lower limb ulceration.
\end{abstract}

\section{Introduction}

Lower limb ulceration is reported as a common problem world-wide, and is considered a major social and economic burden [1]. Lower limb ulceration is associated with numerous comorbidities including, but not limited to; diabetes, peripheral vascular disease and venous insufficiency [2]. The management of ulceration is dependent on the proposed causes, although common interventions may include both non-surgical and surgical approaches [3]. Typically, effective ulcer management involves local wound care, compression therapy, pressure redistribution, infection management and optimization of vascular status $[2,4,5]$. Recently, extracorporeal shock

\footnotetext{
* Correspondence: paul.butterworth@scu.edu.au

'School of Health and Human Sciences, Southern Cross University,

Queensland 4225, Australia

2Lower Extremity and Gait Studies Program, Faculty of Health Sciences, La

Trobe University, Melbourne, Victoria 3086, Australia

Full list of author information is available at the end of the article
}

wave therapy, for the treatment of chronic ulceration, has also gained attention in the literature [6].

The use of extracorporeal shock waves in medicine was first reported over 30 years ago as a treatment for kidney stones [7], and is commonly referred to as 'extracorporeal shock wave lithotripsy', or 'ESWL' [8]. Extracorporeal shock waves are also used as a treatment for musculoskeletal conditions such as plantar heel pain $[9,10]$ and boney non-union [11,12], and is commonly referred to as 'extracorporeal shock wave therapy' (ESWT) to differentiate from ESWL [13]. Furthermore, the use of ESWT has also been reported in the treatment of arterial aneurysms [14] and intermittent claudication [15,16]. Although the mechanisms by which ESWT improves ulcer healing are not fully understood, it is purported to stimulate vascular in-growth, neovascularization and cell proliferation $[17,18]$, therefore improving healing rates in chronic ulcers [1]. Typically, ESWT would entail one to 
two treatments per week, until there is evidence of ulcer healing.

Despite the reported success of ESWT for the treatment of lower limb ulceration, the quality of evidence investigating the effectiveness of this intervention has not been reviewed in detail. Therefore, the aim of this review was to investigate the effectiveness of ESWT for the treatment of lower limb ulceration.

\section{Review}

\section{Types of studies included}

All studies included in this review were obtained from English-language peer reviewed scientific journals investigating the effectiveness of ESWT for lower limb ulceration. All study designs, with the exception of casereports, were eligible for inclusion in this review. Letters to the editor, opinion pieces and editorials were also excluded.

\section{Types of participants included}

Studies were included if the use of ESWT for the treatment of lower limb ulceration was assessed. The category of ulcers included in this review were those of neurovascular origin (i.e. diabetic, neuropathic, neurovascular or vascular). Studies where the participant's ulcer was associated with pressure sores, burns or surgical complications were excluded.

\section{Search strategy for identification of studies}

In December 2013 an electronic database search was conducted using Medical Subject Headings (MeSH), followed by a keyword search strategy. Auto-alerts were developed to provide updates on recent publications until the review was finalised (March 2014). The following databases were searched: Ovid MEDLINE (1966 to date), CINAHL (1982 to date), Web of Knowledge, Scopus and Ovid AMED (from inception). The database search strategy is presented in Table 1.

Upon completion of the search (March 2014), a hand search was performed of references from the studies identified in the electronic search, and Google Scholar was searched in an attempt to identify any further material.

\section{Table 1 Database search strategy}

\begin{tabular}{|c|c|}
\hline \multirow{3}{*}{$\begin{array}{l}\text { Subject term } \\
\text { keywords }\end{array}$} & 1. Exp. Extra corporeal shock wave therapy \\
\hline & $\begin{array}{l}\text { 2. "Extra corporeal shock wave therapy" or ESWT or } \\
\text { "shock wave therapy" or lithotripsy }\end{array}$ \\
\hline & 3. 1 or 2 \\
\hline \multirow{3}{*}{$\begin{array}{l}\text { Subject term } \\
\text { keywords }\end{array}$} & 4. Exp. ulcer \\
\hline & $\begin{array}{l}\text { 5. Lower limb or foot* or leg or arterial or venous or } \\
\text { neuropathic or diabet* }\end{array}$ \\
\hline & 6.4 or 5 \\
\hline Combine & 10. 3 and 6 \\
\hline
\end{tabular}

Two reviewers (PAB and TPW) then independently reviewed titles and abstracts according to the predetermined inclusion criteria. Discrepancies between reviewers regarding eligibility were discussed until consensus was reached. Progression to full text review was then permitted.

\section{Data extraction and analysis}

A predefined data extraction form was used in the extraction process (Additional file 1). Relevant data (means, mean differences, standard deviations and $p$ values) were extracted from studies by two investigators (PAB and TPW), with specific attention to the following variables; study design, participant numbers, mean age, sex, ulcer classification, change in healing and ulcer size and ESWT protocol used. The data pertaining to each study was then assigned a numerical value to ensure the two investigators (PAB and TPW) were blinded to author and publication details during quality assessment. Where disagreements occurred during the quality assessment process, a third assessor (YDP) made the final decision on quality assessment scores. Where studies provided sufficient statistical data, effect size (Cohen's $d$ ) was calculated from means and standard deviations. Effect sizes were categorized as follows: negligible effect $(\geq-0.15$ and $<0.15)$; small effect $(\geq 0.15$ and $<0.40)$; medium effect $(\geq 0.40$ and $<0.75)$; large effect $(\geq 0.75$ and $<1.10)$; very large effect $(\geq 1.10$ and $<1.45)$ and, huge effect $(\geq 1.45)[19,20]$.

\section{Assessment of methodological quality}

Assessment of each study's methodological quality was performed using the Quality Index tool developed by Downs and Black [21]. This tool has been shown to have high internal consistency $(K R-20=0.89)$, good test-retest reliability $(r=0.88)$ and good inter-rater reliability $(r=0.75)$. The Quality Index tool consists of 27 items, and allows for assessment of internal and external validity, reporting and power.

For this systematic review, an a priori decision was made to remove two items where they did not apply to the respective studies identified. Firstly, Item 25 was removed for non-randomised controlled studies, as it has been shown that case mix adjustment cannot reduce the extent of bias in non-randomised trials [22]. Secondly, Item 27 was removed for all studies, as a minimally important difference has not been established for measuring the outcomes of ESWT in the treatment of ulceration.

We chose to present the quality assessment results as percentage scores, which is typical of previous studies using the Quality Index tool [20,23-24]. Furthermore, after obtaining data from the included studies, the findings were combined using a narrative rather than a quantitative approach, owing to study heterogeneity. 


\section{Results}

A total of 555 results were identified through our electronic search (Additional file 2) and one further study from other sources (i.e. as laid out in our search strategy). Upon the removal of duplicates, 123 studies were suitable for initial review. Following the review of titles and abstracts, 25 studies were extracted for full review and finally, five studies were considered appropriate for inclusion (Additional file 3). The reasons for the exclusion of studies are available in Additional file 4. A flow diagram, as described by Moher and colleagues [25], is presented in Figure 1, highlighting the study selection process.

\section{Quality of the evidence}

The inter-rater reliability of the Quality Index scores was not calculated due to the small number of trials included in the review [23]. However, perfect agreement was recorded on all items except item 5 (50\% agreement) and item 13 (65\% agreement). Table 2 indicates that moderate study quality was identified across trials (quality assessment scores ranged from 38 to 63\%, mean $53 \%)$. External validity across studies was rated most poorly, due to deficient definitions of the source population and methods of patient selection, and poor identification of confounding factors. Studies also rated poorly on the internal validity component of the Quality Index.

\section{Trial characteristics}

There were three randomised control trials, one quasiexperimental study and one case-series study identified, the characteristics of which are presented in Table 3. Moretti et al. [26] conducted a randomised controlled study in participants with neuropathic diabetic foot ulcers, to evaluate standard care and ESWT (intervention group) against standard care alone (control group). Both groups received standard care consisting of therapeutic footwear, debridement and dressings, although none of these variables were described in detail. Furthermore, the treatment of infection was undertaken where necessary and was not considered as a reason to exclude participants.

Saggini et al. [27] conducted a quasi-experimental study and investigated 40 participants with chronic posttraumatic, venous and diabetic ulcers (17 venous ulcers, 7 diabetic). The case group $(n=30)$ received ESWT; between ESWT treatment sessions, the participants continued previous conservative treatment, although it is unclear what this treatment consisted of. There were 10 control participants who received regular conservative dressings, although the authors did not explain what conservative care involved.

Wang et al. [28] compared ESWT with hyperbaric oxygen therapy (HBO) in chronic diabetic foot ulcers. Seventy-four participants were randomly divided into two groups according to the dates that they were

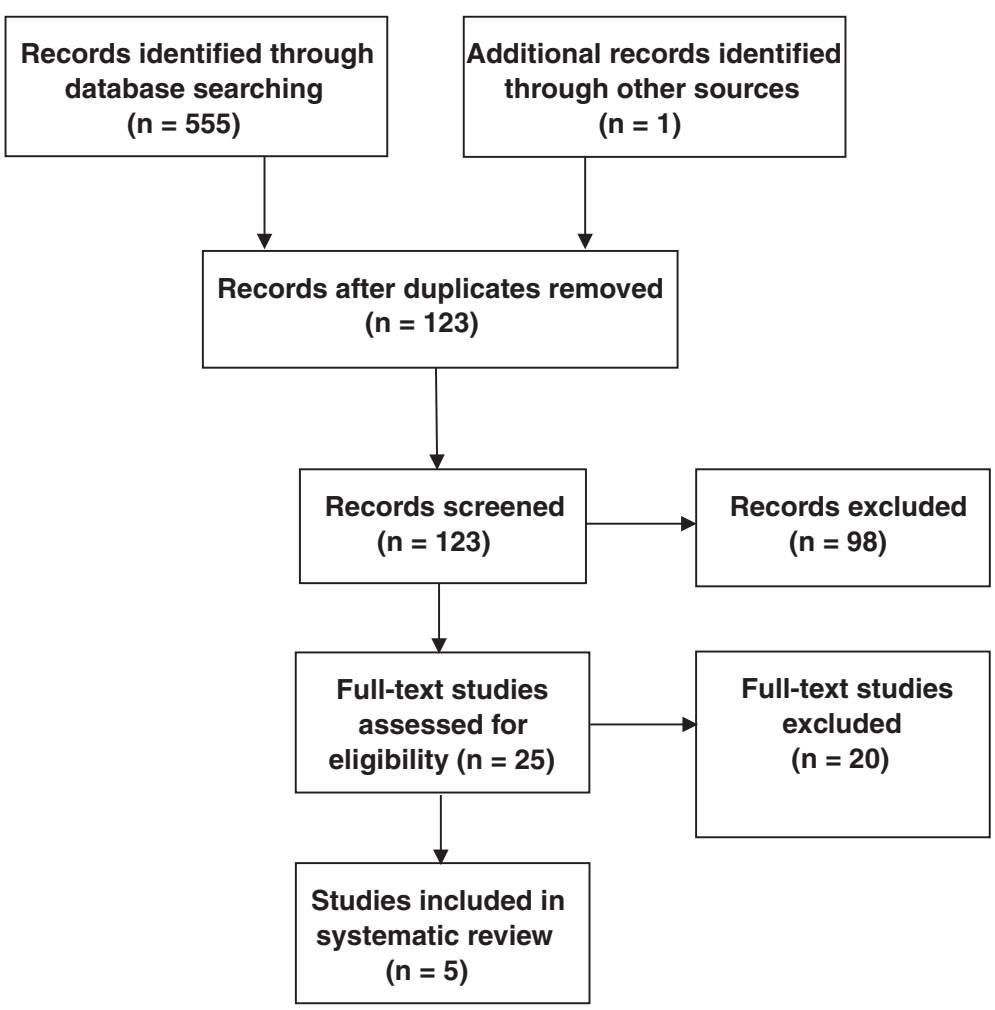

Figure 1 Study selection process. 
Table 2 Quality assessment scores from the Quality index tool [21]

Quality index items

Moretti [26] Saggini [27] Wang [28] Wang [29] Schaden [17]

Reporting

1. Study hypotheses/aim/objective

2. Main outcomes

3. Participant characteristics

4. Interventions of interest

5. Distribution of principal confounders

6. Main findings

7. Estimates of random variability

8. Adverse events described

9. Participants lost to follow up described

10. Actual probability values reported

\section{External validity}

11. Were subjects asked to participate representative of population from which 0 they were recruited?

12. Were subjects prepared to participate representative of the entire 0 population from which they were recruited?

13. Were the staff, places and facilities where the patients were treated, representative of the treatment patients received?

\section{Internal validity (bias)}

14. Was an attempt made to blind study subjects to the intervention they have received?

15. Was an attempt made to blind those measuring the main outcomes of the intervention?

16. If any of the results of the study were based on 'data dredging' was this 1 made clear?

17. Does analysis adjust for lengths of follow up or is the time period between 0 intervention and outcome the same?

18. Were the statistical tests used to assess the main outcomes appropriate?

19. Was compliance with the intervention reliable?

20. Were the main outcome measures used accurate (valid and reliable)?

Internal validity (selection bias)

21. Were cases and controls recruited from the same population?

22. Were cases and controls recruited over the same period of time?

23. Were study subjects randomised to intervention groups?

24. Was randomised intervention assignment concealed from participants/ researchers until recruitment complete?

25. Was there adequate adjustment for confounding in the analysis from which the main findings were drawn?

26. Were losses to follow up of patients taken into account?

Power

27. Did the study have sufficient power to detect a clinically important effect?

Total score\%

$55 \quad 38$

38

52

Notes:

All questions were scored on the following scale: yes $=1$, unable to determine $=0, n o=0$.

Question 5 is an exception with scores allocated: yes $=2$, partially $=1$, no $=0$.

*Item removed. 
Table 3 Characteristics of included studies

\begin{tabular}{|c|c|c|c|c|c|c|c|c|}
\hline $\begin{array}{l}\text { Primary } \\
\text { author }\end{array}$ & Outcomes measured & Study design & $\begin{array}{l}\text { Number allocated to } \\
\text { (a) experimental and } \\
\text { (b) control groups }\end{array}$ & $\begin{array}{l}\text { Mean age } \\
\text { years (SD) }\end{array}$ & $\begin{array}{l}\% \\
\text { female }\end{array}$ & $\begin{array}{l}\text { Mean duration of disease } \\
\text { in months (SD) }\end{array}$ & Ulcer classification & ESWT protocol \\
\hline \multirow[t]{2}{*}{ Moretti [26] } & \multirow{2}{*}{$\begin{array}{l}\text { Rate of re- } \\
\text { epithelialization }\end{array}$} & \multirow[t]{2}{*}{ RCT } & (a) 15 & $56.2 \pm 4.9$ & 40 & UD & \multirow{2}{*}{$\begin{array}{l}\text { Neuropathic (diabetic) plantar } \\
\text { foot ulceration } \geq 6 \text { months } \\
\text { duration; area }>1 \mathrm{~cm}^{2} \text { and } \\
\text { diameter between } 0.5 \text { and } 5 \mathrm{~cm}\end{array}$} & \multirow{2}{*}{$\begin{array}{l}3 \text { sessions (every } 72 \text { hours); } 100 \\
\text { pulses per } 1 \mathrm{~cm}^{2} \text {; EFD } 0.03 \mathrm{~mJ} / \mathrm{mm}^{2}\end{array}$} \\
\hline & & & 15 & $56.8 \pm 7.5$ & 53 & UD & & \\
\hline \multirow[t]{3}{*}{ Saggini [27] } & Exudate, & \multirow{3}{*}{$\begin{array}{l}\text { Quasi- } \\
\text { experimental }\end{array}$} & (a) 30 & 58.5 & 43 & 5.3 & \multirow{3}{*}{$\begin{array}{l}\text { Venous ulcers; diabetic ulcers; } \\
\text { unresponsive to conservative } \\
\text { care for } \geq 3 \text { months duration }\end{array}$} & \multirow{3}{*}{$\begin{array}{l}4 \text { to } 10 \text { sessions; } 100 \text { impulses } \\
\text { per } 1 \mathrm{~cm}^{2} \text {; EFD } 0.037 \mathrm{~mJ} / \mathrm{mm}^{2} \text {; } \\
\text { frequency of } 4 \mathrm{~Hz} \text { or } 240 \\
\text { impulses/min }\end{array}$} \\
\hline & Granulation and & & 10 & 66.6 & 40 & 5.2 & & \\
\hline & Fibrin/necrotic tissue & & & & & & & \\
\hline \multirow[t]{2}{*}{ Wang [28] } & Healing rates & \multirow[t]{2}{*}{$\mathrm{RCT}$} & (a) 34 & $58.6 \pm 12.6$ & UD & $22.7 \pm 20.9$ & \multirow{2}{*}{$\begin{array}{l}\text { Diabetic foot ulcer }>3 \text { months } \\
\text { duration }\end{array}$} & \multirow{2}{*}{$\begin{array}{l}3 \text { treatments; repeat course } \\
\text { performed in cases with } \\
\text { incomplete healing; } 300 \text { plus } \\
100 \text { pulses per } 1 \mathrm{~cm}^{2} ; \text { EFD } 0.11 \mathrm{~mJ} / \\
\mathrm{cm}^{2}\end{array}$} \\
\hline & $\begin{array}{l}\text { Histopathological } \\
\text { analysis }\end{array}$ & & (a) 36 & $63.4 \pm 10.3$ & UD & $19.0 \pm 19.5$ & & \\
\hline \multirow[t]{2}{*}{ Wang [29] } & Healing rates & \multirow[t]{2}{*}{$\mathrm{RCT}$} & (a) 39 & $60.5 \pm 14.0$ & UD & $6^{*}$ (3 to 16$)$ & \multirow{2}{*}{$\begin{array}{l}\text { Diabetic foot ulcer }>3 \text { months } \\
\text { duration }\end{array}$} & \multirow{2}{*}{$\begin{array}{l}6 \text { treatments; Ulcer size dependent } \\
\text { treatment; minimum } 500 \text { pulses; } \\
\text { EFD } 0.27 \mathrm{~mJ} / \mathrm{cm}^{2}\end{array}$} \\
\hline & $\begin{array}{l}\text { Histopathological } \\
\text { analysis }\end{array}$ & & (a) 38 & $62.5 \pm 14.0$ & UD & $6^{*}(6$ to 10$)$ & & \\
\hline Schaden [17] & $\begin{array}{l}\text { Safety and feasibility } \\
\text { of ESWT }\end{array}$ & Case-series & (a) 31 & 61.0 & 48 & UD & $\begin{array}{l}\text { Complicated, non-healing, } \\
\text { acute and chronic venous and } \\
\text { arterial ulcers }\end{array}$ & $\begin{array}{l}\text { Mean sessions } 1.9 \text { to } 3.7 \\
100 \text { impulses per } 1 \mathrm{~cm}^{2} \\
\text { EFD } 0.1 \mathrm{~mJ} / \mathrm{mm}^{2}\end{array}$ \\
\hline
\end{tabular}

Notes:

EFD: energy flux density; RCT: randomised controlled trial.

SD: standard deviation; UD: unable to determine.

*Median value (range) reported.

ESWT $=$ extracorporeal shock wave therapy. 
referred into the study. Thirty-six participants with 38 ulcers received ESWT, whereas 38 participants with 38 ulcers received $\mathrm{HBO}$ therapy. A repeat course of ESWT was performed in cases with incomplete healing from the first course of treatment. Participants resumed the same wound care technique at home after treatment including offloading on the affected leg, wound cleansing with sterile normal saline solution, and application of silver sulfadiazine cream. Participants in the HBO group received the same wound care as the ESWT group. In their second study comparing ESWT with HBO therapy in chronic diabetic foot ulcers, Wang et al. [29] randomly divided participants according to computer generated block labels. Forty-three participants were assigned to the ESWT group and 45 participants were assigned to the HBO group. After ESWT, participants resumed their initial wound care protocol including offloading on the affected foot, wound cleansing with sterile normal saline solution and application of silver sulfadiazine cream. Participants in the HBO group received the same wound care protocol after treatment as the ESWT group.

In a study by Schaden $e t$ al. [17], the safety and feasibility of ESWT was assessed in 208 participants with a variety of wounds that included 31 ulcers of a neurovascular origin. The intervention applied to all participants was a combination of debridement, ESWT and moist wound dressings.

\section{Evidence for the effectiveness of ESWT in the treatment of lower limb ulceration}

Table 4 provides a description of the mean differences of ulcer healing between groups. Moretti et al. [26] found that after 20 weeks of treatment, 53.33\% of the ESWT group had complete wound closure compared with $33.33 \%$ of the control group, and healing times were 60.8 and 82.2 days respectively $(p<0.001)$.

Saggini et al. [27] treated 32 ulcers with ESWT and reported that 16 ulcers healed completely within six sessions of ESWT. In those ulcers that did not completely heal, statistical significance $(\mathrm{p}<0.01)$ was reported with regard to decrease in ulcer size, after four to six sessions of ESWT. There was no evidence in this study of a difference between the two groups regarding ulcer healing or change in ulcer size.

Wang et al. [28] found that in the ESWT group, 31\% of ulcers completely healed, 58\% improved and $11 \%$ remained unchanged. In the HBO group $22 \%$ completely healed, $50 \%$ improved, and $28 \%$ remained unchanged. These differences were significant at $p=0.001$. Furthermore, greater than $50 \%$ improvement of the ulcer was observed in $89 \%$ of participants in the ESWT group and $72 \%$ of participants in the HBO group $(p<0.001)$. In their second study comparing ESWT and HBO, Wang et al. [29] found: completely healed ulcers in 57\% and $25 \%(p=0.003) ; \geq 50 \%$ improved ulcers in $32 \%$ and $15 \%$ $(p=0.071)$, and unchanged ulcers in $11 \%$ and $60 \%$ $(p<0.001)$ respectively.

Schaden et al. [17] found that venous stasis ulcers demonstrated the worst healing rates (36\% versus $66 \%$ for all other ulcers, $p=0.001$ ). Furthermore, arterial insufficiency ulcers did not completely heal in $33 \%$ of cases, the second worst healing rate of all ulcer types. The primary outcome assessed in their study was the safety and feasibility of using ESWT on wounds, the authors concluding that ESWT is a safe and effective treatment.

Table 4 Mean differences in ulcer healing between groups of included studies

\begin{tabular}{|c|c|c|c|c|}
\hline $\begin{array}{l}\text { Primary } \\
\text { author }\end{array}$ & $\begin{array}{l}\text { Difference between groups } \\
\text { ESWT }\end{array}$ & Control & $p$ value & $\begin{array}{l}\text { Effect size } \\
(\text { Cohen's } d)\end{array}$ \\
\hline \multirow[t]{2}{*}{ Moretti [26] } & Wound closure: $53.33 \%$ & $33.33 \%$ & $<0.001$ & UD \\
\hline & healing time: 60.8 days (SD 4.7 days) & 82.2 days (SD 4.7 days) & $<0.001$ & 4.43, Huge effect \\
\hline Saggini [27] & UD & UD & UD & UD \\
\hline \multirow[t]{4}{*}{ Wang [28] } & $31 \%$ completely healed & $22 \%$ completely healed & $<0.001$ & UD \\
\hline & $58 \%$ improved & $50 \%$ improved & $<0.001$ & UD \\
\hline & $11 \%$ remained unchanged. & $28 \%$ remained unchanged & $<0.001$ & UD \\
\hline & $\geq 50 \%$ improved in $89 \%$ of participants & $\geq 50 \%$ improved in $72 \%$ of participants & $<0.001$ & UD \\
\hline \multirow[t]{3}{*}{ Wang [29] } & Completely healed 57\% & Completely healed 25\% & $=0.003$ & UD \\
\hline & $\geq 50 \%$ improved in $32 \%$ of participants & $\geq 50 \%$ improved in $15 \%$ of participants & $=0.071$ & UD \\
\hline & unchanged ulcers in $11 \%$ & unchanged ulcers in $60 \%$ & $<0.001$ & UD \\
\hline Schaden [17] & NA & NA & NA & NA \\
\hline
\end{tabular}

Notes:

UD: unable to determine; NA: not applicable.

ESWT = extracorporeal shock wave therapy.

$\mathrm{SD}=$ standard deviation.

Cohen's $d$ : negligible effect $(\geq-0.15$ and $<0.15)$, small effect $(\geq 0.15$ and $<0.40)$, medium effect $(\geq 0.40$ and $<0.75)$, large effect $(\geq 0.75$ and $<1.10)$, very large effect $(\geq 1.10$ and $<1.45)$, huge effect $(\geq 1.45)$. 


\section{Discussion}

The aim of this systematic review was to investigate the effectiveness of ESWT for the treatment of lower limb ulcers. We evaluated five studies in this review, and identified a trend to suggest that ESWT may be effective in improving wound healing and decreasing wound size. Furthermore, ESWT may also be a safe treatment option with few complications associated with its use, however; we found average study quality for the studies identified. External validity across studies was rated most poorly, due to deficient definitions of the source population and methods of patient selection, and poor identification of confounding factors. It is difficult therefore, to generalise the findings of the studies to the populations from which the study participants were derived. Furthermore, it is unknown whether participants were representative of the population from which they were recruited. As such, all five studies performed poorly on the external validity questions, scoring a mean of only $27 \%$ for questions 11 to 13 on the quality Index tool.

All studies also rated poorly on the internal validity component of the Quality Index (questions 14 to 26). For example, Moretti et al. [26] conducted a randomised controlled study in participants with neuropathic diabetic foot ulcers, to evaluate standard care and ESWT (intervention group) against standard care alone (control group). While it is unclear what standard care comprised of in both groups, it appears that both groups received therapeutic footwear, debridement and dressings, and treatment of infection where present. Subsequently, treatment effects in the intervention group could have been influenced by the variation in the standard care regime, especially where antibiotics were used to treat infection. In the study by Saggini et al. [27], the authors described the control group as receiving usual conservative dressings but did not clearly describe the standard care received by the intervention group. The lack of standardization is of particular concern considering the non-blinded design of the studies. Therefore, the conclusions made by the authors of these studies should be considered in light of these methodological flaws.

The internal validity of the studies identified may also have been threatened due to a loss of participants during the study. While Moretti et al. [26] and Saggini et al. [27] suggested that all participants in their study completed the respective trials; Wang et al. [28] described a loss of four participants during their study, with no reference to how these losses were accounted for in their final analysis. In their second study, Wang et al. [29] described a loss of 11 participants during their trial, again with no discussion or statistical analysis to account for this loss. As there was no reference to an intention-totreat analysis in the studies by Wang et al. [28,29], group characteristics may have changed during the trial, resulting in over-estimation of the treatment effect; only the study by Schaden et al. [17] made an attempt to adjust their statistical analysis with intention-to-treat analysis. Further threats to internal validity might have occurred as no attempt was made to blind those responsible for measuring the outcomes in any of the five studies. Furthermore, the details of randomization in the study by Moretti et al. [26] were not made clear in their study. Consequently, differences in baseline characteristics may have influenced the effects of the intervention.

The classification of ulceration varied across the five studies identified in this review. Moretti et al. [26] defined their inclusion of neuropathic diabetic foot ulceration as occuring below the malleoli for a period of at least 6 months with an area wider than $1 \mathrm{~cm}^{2}$. Although Moretti et al. [26] made an attempt to define peripheral neuropathy and standard care, ulcer classification and measurement of change in ulcer size was not undertaken using a recognised or validated measure. Saggini et al. [27] included venous and diabetic ulcers in those participants with a history of chronic ulcers for more than three months. While Saggini et al. [27] defined a recognised measure of wound exudate, the measurement of change in ulcer size was not appropriately described in their methods. The two studies by Wang et al. [28,29] included participants with recurrent chronic diabetic ulcers of the foot for more than three months duration. In these two studies $[28,29]$, and in the study by Schaden et al. [17], there was no description of a recognised method used to determine the change in ulcer size following the intervention. Consequently, the variation in ulcer classification and the poor definitions of change in ulcer size used across studies renders these results susceptible to bias.

The ESWT protocol varied between studies resulting in study heterogeneity, making comparison difficult. Specifically, there were differences in the duration, frequency and strength of ESWT application identified between studies. Furthermore, these differences were also noticeable within studies. For example, a repeat course of treatment was performed in cases with incomplete healing from the first course of treatment in the study by Wang et al. [28]. Moreover, the ESWT treatment dosage for each participant in the studies by Wang et al. [29] and Schaden et al. [17] was dependent on the size of the participant's ulcer, rather than a pre-determined intervention dose. In the study by Saggini et al. [26], participants' received anywhere between four and 10 sessions of ESWT; essentially, in these three studies, the likelihood of the results being due to the actual intervention cannot be determined.

This systematic review has identified a number of important implications for future research. Firstly, to reduce bias it is essential that when evaluating the effectiveness of ESWT for the treatment of lower limb ulceration, that 
rigorous randomised controlled trial (RCT) methods are used [30,31]. Second, it is necessary that outcome measures used are reliable and valid and include both specific and generic measures [32]. This should also include detailed information about the criteria used to identify the presence of lower limb ulceration as there is substantial variability in the criteria used. Third, acknowledgement and adjustment for confounding variables should be included in future trials and if necessary, stratification of analyses should be made on the basis of the type of ulceration. This will ensure that such trials include sufficient information for the methods to be critiqued and allow comparisons to be made with similar investigations. Finally, the establishment of an optimal ESWT regimen remains to be established and should be the focus of future research.

The existing evidence that supports the use of ESWT for treatment of lower limb ulceration therefore needs to be viewed in light of some limitations. Firstly, there were only two studies (one of which was an RCT) that investigated the effect of ESWT versus standard treatment, and there were small participant numbers in the studies identified. Secondly, this review identified significant methodological heterogeneity between studies. For example; one of the studies in this review included smokers and also assessed ulceration associated with multiple comorbidities [27], whereas the other three studies did not. Third, the outcome measures assessed across studies was inconsistent; although all studies assessed the change in ulcer size or ulcer healing rates as their primary outcome, the definitions used to determine these changes varied between studies. There were some limitations to our review design; there was no pooling of data for meta-analysis and no statistical measure of heterogeneity performed. There were however, two strengths of this review; the use of a validated quality assessment tool [20], and the systematic approach used.

\section{Conclusions}

This systematic review identified five studies that reported on the effectiveness of ESWT for the treatment of lower limb ulcers. There is limited evidence to support ESWT as a treatment for lower limb ulceration. Considering this, further research is needed to support the use of ESWT in the treatment of lower limb ulceration.

\section{Additional files}

Additional file 1: Data extraction rorm. Contains a copy of the form used to extract data from the studies included in this systematic review.

Additional file 2: Search results by database. Contains the results of the electronic database search for this systematic review.

Additional file 3: Included studies. Contains a list of included studies in this systematic review.
Additional file 4: Reasons for the exclusion of studies after full text assessment. Contains a list of studies excluded from this systematic review.

\section{Competing interests}

The authors declare that they have no competing interests.

\section{Authors' contributions}

The search strategy was performed by PAB, SAN and ADC. Data extraction was performed by PAB and TPW. Quality analysis was performed by PAB, TPW and YDP. All authors provided input into the review draft and agreed on the final manuscript. All authors read and approved the final manuscript.

\section{Author details}

${ }^{1}$ School of Health and Human Sciences, Southern Cross University, Queensland 4225, Australia. 'Lower Extremity and Gait Studies Program, Faculty of Health Sciences, La Trobe University, Melbourne, Victoria 3086, Australia. ${ }^{3}$ School of Medicine, Faculty of Medicine, Nursing and Health Science, Flinders University South Australia, Adelaide 5042, Australia. ${ }^{4}$ Department of Anatomy II, Ludwig-Maximilians-University of Munich, Munich 80336, Germany.

Received: 27 May 2014 Accepted: 22 December 2014

Published online: 05 February 2015

\section{References}

1. Fioramonti P, Onesti MG, Fino P, Fallico N, Scuderi N. Extracorporeal shock wave therapy for the treatment of venous ulcers in the lower limbs. Ann Ital Chir. 2012:83(1):41-4.

2. Mittermayr R, Antonic $V$, Hartinger J, Kaufmann $H$, Redl H, Téot $L$, et al. Extracorporeal shock wave therapy (ESWT) for wound healing: technology, mechanisms, and clinical efficacy. Wound Repair Regen. 2012;20(4):456-65.

3. Attinger CE, Janis JE, Steinberg J, Schwartz J, Al-Attar A, Couch K. Clinical approach to wounds: debridement and wound bed preparation including the use of dressings and wound-healing adjuvants. Plast Reconstr Surg. 2006;117 Suppl 7:72-109.

4. Ogrin R, Houghton PE, Thompson GW. Effective management of patients with diabetes foot ulcers: outcomes of an interprofessional diabetes foot ulcer team. Int Wound J. 2013. doi:10.1111/iwj.12119

5. Tang JC, Marston WA, Kirsner RS. Wound Healing Society (WHS) venous ulcer treatment guidelines: what's new in five years? Wound Repair Regen. 2012;20(5):619-37.

6. Qureshi AA, Ross KM, Ogawa R, Orgill D. Shock wave therapy in wound healing. Plast Reconstr Surg. 2011;128(6):721e-7. doi:10.1097/PRS.0b013e318230c7d1.

7. Chaussy C, Brendel W, Schmiedt E. Extracorporeally induced destruction of kidney stones by shock waves. Lancet. 1980;2:1265-8.

8. Rassweiler JJ, Knoll T, Köhrmann KU, McAteer JA, Lingeman JE, Cleveland $\mathrm{RO}$, et al. Shock wave technology and application: an update. Eur Urol. 2011:59:784-96.

9. Thomson CE, Crawford F, Murray GD. The effectiveness of extra corporeal shock wave therapy for plantar heel pain: a systematic review and meta-analysis. BMC Musculoskelet Disord. 2005;6:19.

10. Schmitz C, Császár NB, Rompe JD, Chaves H, Furia JP. Treatment of chronic plantar fasciopathy with extracorporeal shock waves. J Orthop Surg Res. 2013:8:31.

11. Biedermann R, Martin A, Handle G, Auckenthaler T, Bach C, Krismer M. Extracorporeal shock waves in the treatment of nonunions. J Trauma. 2003;54:936-42.

12. Cacchio A, Giordano L, Colafarina O, Rompe JD, Tavernese E, loppolo F, et al. Extracorporeal shock wave therapy compared with surgery for hypertrophic long-bone nonunions. J Bone Joint Surg Am. 2009;91:2589-97.

13. Speed C. A systematic review of shockwave therapies in soft tissue conditions: focusing on the evidence. Br J Sports Med. 2013. doi:10.1136/ bjsports-2012-091961

14. Tse GH, Qazi HA, Halsall AK, Nalagatla SRK. Shockwave llithotripsy: arterial aneurysms and vascular complications. J Endourol. 2011;25(3):403-11.

15. Serizawa F, Ito K, Sato A, Shimokawa H. Non-invasive extracorporeal shock wave therapy ameliorates walking ability in patients with peripheral artery disease and intermittent claudication [Abstract]. Circulation. 2010;122:21. 
16. Serizawa F, Ito K, Kawamura K, Tsuchida K, Hamada Y, Zukeran T, et al. Extracorporeal shock wave therapy improves the walking ability of patients with peripheral artery disease and intermittent claudication. Circ J. 2012;76 (6):1486-93.

17. Schaden W, Thiele R, Kölpl C, Pusch M, Nissan A, Attinger CE, et al. Shock wave therapy for acute and chronic soft tissue wounds: a feasibility study. J Surg Res. 2007;143(1):1-12.

18. Contaldo C, Högger DC, Khorrami Borozadi M, Stotz M, Platz U, Forster N, et al. Radial pressure waves mediate apoptosis and functional angiogenesis during wound repair in ApoE deficient mice. Microvasc Res. 2012;84:24-33.

19. Thalheimer W, Cook S. How to calculate effect sizes from published research articles: a simplified methodology. http://www.bwgriffin.com/gsu/ courses/edur9131/content/Effect_Sizes_pdf5.pdf.

20. Butterworth PA, Landorf KB, Smith SE, Menz HB. The association between body mass index and musculoskeletal foot disorders: a systematic review. Obes Rev. 2012;13(7):630-42.

21. Downs SH, Black N. The feasibility of creating a checklist for the assessment of the methodological quality both of randomised and non-randomised studies of health care interventions. J Epidemiol Community Health. 1998;52(6):377-84.

22. Deeks JJ, Dinnes J, D'Amico R, Sowden AJ, Sakarovitch C, Song F, et al. Evaluating non-randomised intervention studies. Health Technol Assess. 2003;7(27):1-173.

23. Cotchett MP, Landorf KB, Munteanu SE. Effectiveness of dry needling and injections of myofascial trigger points associated with plantar heel pain: a systematic review. J Foot Ankle Res. 2010;3:18.

24. McMillan AM, Landorf KB, Barrett JT, Menz HB, Bird AR. Diagnostic imaging for chronic plantar heel pain: a systematic review and meta-analysis. J Foot Ankle Res. 2009;2:32.

25. Moher D, Liberati A, Tetzlaff J, Altman DG. Preferred reporting items for systematic reviews and meta-analyses: the PRISMA statement. PLoS Med. 2009;6(7):e1000097.

26. Moretti B, Notarnicola A, Maggio G, Moretti L, Pascone MT, Silvio V. The management of neuropathic ulcers of the foot in diabetes by shock wave therapy. BMC Musculoskel Dis. 2009;10(1):54.

27. Saggini R, Figus A, Troccola A, Cocco V, Saggini A, Scuderi N. Extracorporeal shock wave therapy for management of chronic ulcers in the lower extremities. Ultrasound Med Biol. 2008;34(8):1261-71.

28. Wang CJ, Kuo YR, Wu RW, Liu RT, Hsu CS, Wang FS, et al. Extracorporeal shockwave treatment for chronic diabetic foot ulcers. J Surg Res. 2009;152 (1):96-103.

29. Wang C-J, Wu R-W, Yang Y-J. Treatment of diabetic foot ulcers: a comparative study of extracorporeal shockwave therapy and hyperbaric oxygen therapy. Diabetes Res Clin Pr. 2011;92(2):187-93.

30. Chalmers TC, Smith Jr H, Blackburn B. A method for assessing the quality of a randomized control trial. Control Clin Trials. 1981:2:31-49.

31. Jadad AR, Moore RA, Carrol D. Assessing the quality of reports of randomised clinical trials. Is blinding necessary? Control Clin Trials. 1996;17:1-12.

32. Landorf KB, Burns J. Health outcome assessment. In: Yates B, editor. Merriman's assessment of the lower limb. 3rd ed. Edinburgh: Elsevier; 2009. p. 33-51.

\section{Submit your next manuscript to BioMed Central and take full advantage of:}

- Convenient online submission

- Thorough peer review

- No space constraints or color figure charges

- Immediate publication on acceptance

- Inclusion in PubMed, CAS, Scopus and Google Scholar

- Research which is freely available for redistribution 